IOS Press

\title{
Editorial
}

\section{Alzheimer's Disease Patients in the Crosshairs of COVID-19}

\author{
George Perry, Ph.D. \\ Department of Biology, The University of Texas at San Antonio, San Antonio, USA \\ E-mail: George.Perry@utsa.edu.
}

In just a few months, COVID-19 (COVID) has transformed our lives: everything about work, education, and interpersonal relations is altered. Among all the changes, increased vulnerability of Alzheimer's disease (AD) patients to death is one of the most striking. Up to $80 \%$ of those dying of COVID are in long-term care, translating to the possibility that over a third of mortality are those afflicted with AD [1], since approximately half of those in long-term care have $\mathrm{AD}$ [2]. There are numerous reports as to why long-term care patients are particularly susceptible to COVID, with close cohabitation being a major factor. AD's comorbidities further align with COVID's risk factors: diabetes, heart disease, and minority status. Significantly, respiratory issues are common among most late-stage $\mathrm{AD}$ patients. The recent finding that risk of death from COVID shares the most important AD susceptibility gene, Apolipoprotein E4, also reinforces the link [3].

All this calls out for careful study to determine the actual numbers of AD patients infected and dying of COVID. Knowledge of the extent and how to protect AD patients is imperative to this vulnerable population and their families.

\section{REFERENCES}

[1] Yourish K, Lai KKR, Ivory D, Smith M (2020) One-Third of All U.S. Coronavirus Deaths Are Nursing Home Residents or Workers. New York Times, May 09, 2020 https://www.nytimes.com/interactive/2020/05/09/us/coronavirus-cases-nursing-homes-us.html

[2] National Center for Health Statistics, Vital and Health Statistics. Series 3, page 22, 2019 https://www.cdc.gov/nchs/data/ series/sr_03/sr03_43-508.pdf

[3] Kuo CL, Pilling LC, Atkins JL, Masoli JAH, Delgado J, Kuchel GA, Melzer D (2020) The APOE e4 genotype predicts severe COVID-19 in the UK Biobank community cohort. J Gerontol A Biol Sci Med Sci, doi: 10.1093/gerona/glaa131 